\title{
Sistem Pakar Mendiagnosa Penyakit Ephelis (Flek Hitam) Pada Kulit Wajah Menggunakan Metode Teorema Bayes
}

\author{
Nur Indah Ramadani Lubis*, Saniman**, Jufri Halim** \\ * Program Studi Sistem Informasi, STMIK Triguna Dharma \\ ** Program Studi Sistem Informasi, STMIK Triguna Dharma
}

\begin{tabular}{l}
\hline \hline Article Info \\
\hline Article history: \\
Received Jan $02^{\text {th }}, 2022$ \\
Revised Jan $15^{\text {th }}, 2022$ \\
Accepted Jan $27^{\text {th }}, 2022$
\end{tabular}

\section{Keyword:}

Ephelis (Flek Hitam)

Bintik-Bintik

Kulit

Sistem Pakar

Teorema Bayes

\begin{abstract}
Flek hitam atau yang disebut juga sebagai Ephelis merupakan bintik yang terdapat pada kulit. Bintik-bintik ini permukaannya rata, berbentuk bulat. Biasanya muncul pada kulit yang terkena paparan sinar matahari yang berulang. Flek hitam paling sering ditemukan pada orang-orang berkulit putih. Penyakit Ephelis pada wajah merupakan sesuatu yang tidak dapat di tentukan secara pasti, hal ini bersifat relatif dan subjektif untuk setiap pasien berdasarkan gejala yang di rasakan. Didalam Sistem Pakar ada banyak Metode yang digunakan salah satunya ialah metode Teorema Bayes, Teorema Bayes digunakan untu menghitung suatu keputusan dan informasi yang tepat dan berdasarkan ovservasi yang telah dilakukan. Sistem pakar dapat menggantikan peran seorang pakar yang prinsip kerjanya dapat memberikan hasil yang pasti, seperti yang di lakukan oleh seorang pakar. Dari penelitian ini menghasilkan aplikasi sistem yang dapat membantu Dokter didalam penanganan masalah pada penyakit Ephelis. Dengan konsep sistem pakar yang merupakan sebuah program yang mampu menganalisis permasalahan dan menghasilkkan kesimpulan dengan adanya proses pemindahan pengetahuan ahli ke dalam sistem.
\end{abstract}

Copyright () 2022 STMIK Triguna Dharma. All rights reserved.

\section{Corresponding Author:*}

Nama : Nur Indah Ramadani Lubis

Program Studi : Sistem Informasi

STMIK Triguna Dharma

Email: nurindahramadani26@gmail.com

\section{PENDAHULUAN}

Kulit merupakan organ yang memiliki peran, diantaranya sebagai pelindung tubuh dari hal-hal yang dapat membahayakan, sebagai alat pengeluaran berupa kelenjar keringat, sebagai alat indra peraba, pengatur suhu tubuh serta sebagai pelindung organ dibawahnya. Dengan adanya kulit yang menjadi bagian terluar tubuh, maka tubuh dapat terhindar dari berbagai ancaman seperti mikroorganisme yang berbahaya, sinar matahari, mengurangi kerusakan akibat terbentur, serta melindungi kontak langsung dengan zat kimia. Maka dari itu sangat penting menjaga kebersihan kulit agar tetap sehat.

Kulit wajah merupakan bagian kulit yang sangat penting untuk dirawat agar orang-orang merasa percaya diri dengan penampilannya. Banyak orang yang menginginkan wajah cantik dan berkulit putih agar tampil menarik dan lebih percaya diri, namun sebenarnya hal yang paling penting adalah mempunyai wajah yang sehat, bersih dan tentunya terawat. Terbukti dengan banyak masyarakat terutama remaja dan ibu-ibu yang sering memiliki penyakit kulit wajah dan menyebabkan seseorang menjadi tidak percaya diri[1].

Flek hitam termasuk penyakit kulit yang sering terjadi pada wajah. Flek hitam atau ephelis merupakan bintikbintik kecil pada kulit yang berwarna lebih gelap dari pada area di sekelilingnya. Flek hitam muncul karena adanya peningkatan produksi melanin di kulit, terutama setelah terpapar sinar matahari atau sinar ultraviolet. Melanin adalah pigmen alami yang menentukan warna kulit seseorang. Flek hitam muncul ketika kulit menyerap sinar ultraviolet, sehingga dapat menyebabkan peningkatan produksi melanin[2].

Lambatnya pengetahuan tentang jenis penyakit kulit pada wajah dan tentang cara pencegahan serta pengobatan mengakibatkan seseorang terkena penyakit kulit tingkat akut. Dalam kasus seperti ini seorang 
pasien membutuhkan seorang ahli untuk mengetahui lebih dini gejala-gejala penyakit pada kulit wajah agar dapat memberikan pencegahan lebih awal. Permasalahan yang sering terjadi adalah ketersediaan dokter ahli atau pakar yang memiliki pengetahuan dibidang tertentu dengan jam kerja prakteknya yg cukup terbatas. Sementara banyak pasien yang harus segera diketahui penyakitnya dan segera ditangani. Sesuai dengan permasalahan diatas maka dibutuhkan suatu sistem yang dapat membantu para pekerja dalam menggantikan ketidak-hadiran dokter ahli atau pakar untuk memberikan informasi dalam mendiagnosa awal penyakit Ephelis (flek hitam) dengan gejala-gejala yang dialami sehingga di temukan solusi yang tepat dengan jenis penyakit yang diderita pasien.

Sistem pakar (expert system) adalah sistem yang berusaha mengapdosi pengetahuan manusia ke komputer, agar komputer dapat menyelesaikan masalah seperti yang dilakukan oleh para ahli. Kecerdasan buatan yang dimaksud disini merujuk pada mesin yang mampu berfikir, menimbang tindakan yang akan diambil dan mampu mengambil keputusan seperti yang dilakukan manusia [3]. Manfaat dan kemampuan sistem pakar adalah meningkatkan output dan produktivitas, menyerap keahlian langka, fleksibilitas, operasi peralatan yang lebih mudah dan transfer pengetahuan kelokasi terpencil [4]. Salah satu metode yang di pakai untuk mendiagnosa penyakit Ephelis (Flek Hitam) adalah metode Teorema Bayes.

Teorema Bayes merupakan salah satu metode yang mengidentifikasi ukuran kepastian terhadap suatu fakta atau aturan, untuk menggambarkan tingkat keyakinan pakar terhadap masalah yang sedang dihadapi, dengan menggunakan Teorema bayes untuk menghitung probabilitas terjadinya suatu peristiwa berdasarkan pengaruh yang di dapat dari hal observasi [5].

\section{METODE PENELITIAN}

Metode penelitian merupakan langkah yang dilakukan untuk mengumpulkan data dan informasi yang dibutuhkan oleh seorang pengembang perangkat lunak (software) sebagai tahapan serta gambaran penelitian yang akan dibuat. Berikut adalah metode dalam penelitian ini yaitu:

\subsection{Data Penyakit}

Berikut tabel 1 adalah data penyakit yang didapatkan dalam penyelesaian masalah terkait mendiagnosis penyakit Ephelis (Flek Hitam) :

Tabel 1. Data Penyakit Ephelis

\begin{tabular}{|c|c|c|}
\hline $\begin{array}{c}\text { Nama } \\
\text { Penyakit }\end{array}$ & Gejala Penyakit & Solusi \\
\hline Melasma & $\begin{array}{l}\text { Muncul warna cokelat kehitaman } \\
\text { pada wajah } \\
\text { Memakai kontrasepsi hormonal } \\
\text { Terjadi pada saaat kehamilan } \\
\text { Pemakaian kosmetik } \\
\text { Defisiensi nutrisi } \\
\text { Terjadi karena adanya kelenjar } \\
\text { Terjadi pada saat Stres }\end{array}$ & $\begin{array}{l}\text { Gunakan obat topikal yang dioleskan } \\
\text { dengan kandungan hidrokuinon, asam } \\
\text { azalea, asam kojic, arbutin dan } \\
\text { tretinoin. Sebagai treatment tambahan } \\
\text { dapat dilakukan tindakan seperti } \\
\text { chemical peeling, laser dan } \\
\text { mikrodermabrasi. Pengobatan melasma } \\
\text { tentunya membutuhkan waktu yang } \\
\text { cukup lama, minimal empat minggu } \\
\text { hasil pengobatan sudah dapat terlihat } \\
\text { namun hanya sampai beberapa bulan. } \\
\text { Selain itu Hindari sinar matahari } \\
\text { langsung (07.00 s/d 16.00). }\end{array}$ \\
\hline Freckles & $\begin{array}{l}\text { Muncul warna cokelat kehitaman } \\
\text { pada wajah } \\
\text { Pemakaian kosmetik } \\
\text { Ada bekas jerawat } \\
\text { Menggunakan obat tertentu yg dapat } \\
\text { merangsang hipermentasi kulit } \\
\text { Sering terkena sinar matahari }\end{array}$ & $\begin{array}{l}\text { Siapkan } 1 \text { buah jeruk lemon belah } \\
\text { menjadi } 2 \text { bagian. Gosokkan dengan } \\
\text { lembut ke wajah. } \\
\text { Selain itu sebaiknya hindari paparan } \\
\text { sinar matahari secara langsung dengan } \\
\text { menggunakan tabir surya sebelum } \\
\text { beraktivitas di luar ruangan. } \\
\text { mengurangi minuman yang } \\
\text { mengandung kafein. }\end{array}$ \\
\hline
\end{tabular}




\subsection{Data Gejala}

Berikut tabel 2 merupakan data gejala yang didapatkan dalam penyelesaian masalah terkait mendiagnosis penyakit Ephelis (Flek Hitam):

Tabel 2. Gejala Penyakit Ephelis (Flek Hitam)

\begin{tabular}{ccl}
\hline No & Kode Gejala & \multicolumn{1}{c}{ Gejala } \\
\hline 1 & G01 & Muncul warna cokelat kehitaman pada wajah \\
2 & G02 & Memakai kontrasepsi hormonal \\
3 & G03 & Terjadi pada saaat kehamilan \\
4 & G04 & Defisiensi Nutrisi \\
5 & G05 & Terjadi karena adanya kelenjar \\
6 & G06 & Terjadi pada saat stres \\
7 & G07 & Pemakaian kosmetik \\
8 & G08 & Ada bekas jerawat \\
9 & G09 & Menggunakan obat tertentu yg dapat merangsang hipermentasi \\
10 & kulit & Sering terkena sinar matahari \\
\hline
\end{tabular}

\subsection{Algoritma Sistem}

Algoritma sistem merupakan tahapan penting yang berguna untuk mengetahui langkah-langkah yang dilakukan sebuah sistem dalam memproses dan menyelesaikan suatu permasalahan.

1. Menentukan Mesin Inferensi

Dari tabel diatas maka rule yang dapat dibentuk untuk mendiagnosis penyakit Ephelis adalah:

Rule $1 \quad$ : IF Muncul warna cokelat kehitaman pada wajah

$A N D$ Memakai kontrasepsi hormonal

$A N D$ Terjadi pada saaat kehamilan

AND Pemakaian kosmetik

$A N D$ Disfungsi hati

$A N D$ Terjadi karena disfungsi endokrin

$A N D$ Terjadi pada saat stres

$A N D$ Sering terkena sinar matahari

\section{THEN Melasma}

Rule 2 : IF Muncul warna cokelat kehitaman pada wajah $A N D$ Pemakaian kosmetik

$A N D$ Ada bekas jerawat

$A N D$ Menggunakan obat tertentu yang dapat merangsang hipermentasi kulit

$A N D$ Sering terkena sinar matahari

THEN Freckles

\section{Menentukan Nilai Probabilitas}

Dibawah ini merupakan tabel nilai dari gejala-gejala penyakit Ephelis (flek hitam) yang didapat dari data riwayat pasien yang mengalami suatu penyakit Ephelis yang telah melakukan konsultasi, dimana data terebut akan digunakan untuk mencari nilai probabilitas atau nilai gejala sebagai nilai untuk mendapatkan nilai kesimpulan bayes. Adapun nilai probabilitas dari gejala penyakit Ephelis (flek hitam) pada tabel 3 sebagai berikut :

Tabel 3. Data Riwayat Pasien

\begin{tabular}{|c|c|c|c|c|c|c|c|c|c|c|c|c|}
\hline \multirow{2}{*}{$\begin{array}{l}\text { Nama } \\
\text { Pasien }\end{array}$} & \multirow{2}{*}{$\begin{array}{l}\text { Nama } \\
\text { Penyakit }\end{array}$} & \multirow{2}{*}{ Kode } & \multicolumn{10}{|c|}{ Gejala } \\
\hline & & & G1 & G2 & G3 & G4 & G5 & G6 & G7 & G8 & G9 & G10 \\
\hline
\end{tabular}




\begin{tabular}{|c|c|c|c|c|c|c|c|c|c|c|c|c|}
\hline James & Melasma & $\mathrm{P} 1$ & & & $*$ & $*$ & & & $*$ & & & \\
\hline Irwan & Melasma & $\mathrm{P} 1$ & & $*$ & & & & & $*$ & & & $*$ \\
\hline Bianca & Melasma & $\mathrm{P} 1$ & & & & & & * & & & & * \\
\hline Tulus & Melasma & $\mathrm{P} 1$ & & & & & * & * & & & & \\
\hline Fitri & Melasma & $\mathrm{P} 1$ & & $*$ & * & & & & & & & * \\
\hline Josua & Melasma & $\mathrm{P} 1$ & & * & & & & & & & & \\
\hline Angel & Melasma & $\mathrm{P} 1$ & & & * & & * & & & & & * \\
\hline Koles & Melasma & $\mathrm{P} 1$ & $*$ & & & & & $*$ & & & & \\
\hline Rius & Melasma & $\mathrm{P} 1$ & $*$ & & & & & & $*$ & & & \\
\hline Indah & Melasma & $\mathrm{P} 1$ & $*$ & & * & & & & $*$ & & & * \\
\hline Kartini & Freckles & $\mathrm{P} 2$ & & & & & & & $*$ & $*$ & & \\
\hline Lasro & Freckles & $\mathrm{P} 2$ & & & & & & & & & & $*$ \\
\hline Maret & Freckles & $\mathrm{P} 2$ & & & & & & & $*$ & & & \\
\hline Sait & Freckles & $\mathrm{P} 2$ & & & & & & & & & & * \\
\hline Dirwan & Freckles & $\mathrm{P} 2$ & & & & & & & & & $*$ & \\
\hline Mastiur & Freckles & $\mathrm{P} 2$ & $*$ & & & & & & $*$ & & & \\
\hline Joel & Freckles & $\mathrm{P} 2$ & & & & & & & & * & & \\
\hline Dodi & Freckles & $\mathrm{P} 2$ & & & & & & & & & & * \\
\hline Rahel & Freckles & $\mathrm{P} 2$ & & & & & & & $*$ & & & $*$ \\
\hline Dewi & Freckles & $\mathrm{P} 2$ & $*$ & & & & & & & $*$ & & \\
\hline
\end{tabular}

Nilai Probabilitas didapat dari jumlah gejala sebagai total penyakit.

$\mathrm{P} 01=$ Melasma

$$
p(A \mid B)=\frac{P(B \cap A)}{P(B)}
$$

Pada data gejala untuk penyakit Melasma yaitu 10 data maka :

$$
\begin{aligned}
& \mathrm{G} 01=\frac{\mathrm{a}}{\mathrm{g}}=0.4 \\
& \mathrm{G} 02=\frac{\mathrm{g}}{\mathrm{g}}=0.4 \\
& \mathrm{G} 03=\frac{4}{9}=0.5 \\
& \mathrm{G} 04=\frac{1}{9}=0.1 \\
& \mathrm{G} 05=\frac{2}{9}=0.3 \\
& \mathrm{G} 06=\frac{9}{9}=0.4 \\
& \mathrm{G} 07=\frac{4}{8}=0.5 \\
& \mathrm{G} 10=\frac{5}{8}=0.6
\end{aligned}
$$

$\mathrm{P} 02=$ Freckles

Pada data gejala untuk penyakit Freckles yaitu 10 data maka :

$$
\begin{aligned}
& \mathrm{G} 01=\frac{2}{5}=0.4 \\
& \mathrm{G} 07=\frac{4}{5}=0.8 \\
& \mathrm{G} 08=\frac{3}{5}=0.6 \\
& \mathrm{G} 09=\frac{1}{5}=0.2 \\
& \mathrm{G} 10=\frac{4}{5}=0.8
\end{aligned}
$$

Dari proses perhitungan diatas maka didapat nilai probabilitas setiap gejala berdasarkan jenis penyakit. Berikut adalah tabel 4 merupakan nilai probabilitas setiap gejala. 
Tabel 4. Nilai Probabilitas

\begin{tabular}{|c|c|c|c|c|}
\hline No & $\begin{array}{c}\text { Jenis } \\
\text { Penyakit }\end{array}$ & $\begin{array}{c}\text { Kode } \\
\text { Gejala }\end{array}$ & Gejala & $\begin{array}{c}\text { Nilai } \\
\text { Probabilitas }\end{array}$ \\
\hline \multirow{8}{*}{1.} & \multirow{8}{*}{ Melasma } & G01 & $\begin{array}{l}\text { Muncul warna cokelat kehitaman pada } \\
\text { wajah }\end{array}$ & 0,4 \\
\hline & & G02 & Memakai kontrasepsi hormonal & 0,4 \\
\hline & & G03 & Terjadi pada saaat kehamilan & 0,5 \\
\hline & & G04 & Defisiensi nutrisi & 0,1 \\
\hline & & G05 & Terjadi karena adanya kelenjar & 0,3 \\
\hline & & G06 & Terjadi pada saat Stres & 0,4 \\
\hline & & G07 & Pemakaian kosmetik & 0,5 \\
\hline & & G10 & Sering terkena sinar matahari & 0,6 \\
\hline \multirow{5}{*}{2.} & \multirow{5}{*}{ Freckles } & G01 & $\begin{array}{l}\text { Muncul warna cokelat kehitaman pada } \\
\text { wajah }\end{array}$ & 0,4 \\
\hline & & G07 & Pemakaian kosmetik & 0.8 \\
\hline & & G08 & Ada bekas jerawat & 0,6 \\
\hline & & G09 & $\begin{array}{l}\text { Menggunakan obat tertentu yg dapat } \\
\text { merangsang hipermentasi kulit }\end{array}$ & 0,2 \\
\hline & & G10 & Sering terkena sinar matahari & 0,8 \\
\hline
\end{tabular}

\section{ANALISA DAN HASIL}

\subsection{Penerapan Metode Teorema Bayes}

Berikut ini merupakan contoh kasus yang menunjukkan adanya suatu gejala dari penyakit Ephelis (Flek Hitam). Seorang pasien pada penyakit Ephelis(flek hitam) mengalami gejala kemudian pasien melakukan suatu konsultasi kepada Dokter Mima dari 10 pilihan gejala yang akan diberikan kepada pasien, terlihat pada tabel 5 berikut.

Tabel 5. Konsultasi

\begin{tabular}{|c|c|c|c|}
\hline No & Kode Gejala & Gejala & Jawaban \\
\hline 1 & G01 & $\begin{array}{l}\text { Muncul warna cokelat kehitaman pada } \\
\text { wajah }\end{array}$ & $\mathrm{Ya}$ \\
\hline 2 & G02 & Memakai kontrasepsi hormonal & Tidak \\
\hline 3 & G03 & Terjadi pada saaat kehamilan & $\mathrm{Ya}$ \\
\hline 4 & G04 & Defisiensi nutrisi & Tidak \\
\hline 5 & G05 & Terjadi karena adanya kelenjar & Tidak \\
\hline 6 & G06 & Terjadi Pada saat Stres & Tidak \\
\hline 7 & G07 & Pemakaian kosmetik & $\mathrm{Ya}$ \\
\hline
\end{tabular}




\begin{tabular}{llll}
\hline 8 & G08 & Ada bekas jerawat & Ya \\
9 & G09 & $\begin{array}{l}\text { Menggunakan obat tertentu yg dapat } \\
\text { merangsang hipermentasi kulit }\end{array}$ & Ya \\
10 & G10 & Sering terkena sinar matahari & Ya \\
\hline
\end{tabular}

Berikut ini adalah langkah-langkah penyelesaiannya yaitu sebagai berikut:

1. Setelah nilai probabilitas sudah didapat, maka selanjutnya akan dijumlahkan nilainya. Berdasarkan data sampel baru yang bersumber dari tabel gejala.

$$
\sum_{G n}^{n} k=1=G 1+\cdots+G n
$$

$$
\begin{aligned}
& \text { a. } \mathrm{P} 01=\text { Melasma } \\
& \mathrm{G} 01=\mathrm{P}\left(\mathrm{E} \mid \mathrm{H}_{1}\right)=0.4 \\
& \mathrm{G} 03=\mathrm{P}\left(\mathrm{E} \mid \mathrm{H}_{3}\right)=0.5 \\
& \mathrm{G} 07=\mathrm{P}\left(\mathrm{E} \mid \mathrm{H}_{7}\right)=0.5 \\
& \mathrm{G} 10=\mathrm{P}\left(\mathrm{E} \mid \mathrm{H}_{10}\right)=0.6 \\
& \sum_{\text {Gn }}^{n} k=4=0.4+0.5+0.5+0.6=2
\end{aligned}
$$

b. $\mathrm{P} 02=$ Freckles

$$
\begin{aligned}
& \mathrm{G} 01=\mathrm{P}\left(\mathrm{E} \mid \mathrm{H}_{1}\right)=0.4 \\
& \mathrm{G} 07=\mathrm{P}\left(\mathrm{E} \mid \mathrm{H}_{7}\right)=0.8 \\
& \mathrm{G} 08=\mathrm{P}\left(\mathrm{E} \mid \mathrm{H}_{8}\right)=0.6 \\
& \mathrm{G} 09=\mathrm{P}(\mathrm{E} \mid \mathrm{H})=0.2 \\
& \mathrm{G} 10=\mathrm{P}\left(\mathrm{E} \mid \mathrm{H}_{10}\right)=0.8
\end{aligned}
$$

$\sum_{G n}^{n} k=5=0.4+0.8+0.6+0.2+0.8=2.8$

2. Mencari probabilitas hipotesa $\mathrm{H}$ tanpa memandang evidence dengan cara membagikan nilai probabilitas evidence awal dengan hasil penjumlahan probabilitas berdasarkan data sampel baru.

$$
\mathrm{P}\left(\mathrm{H}_{\mathrm{i}}\right)=\frac{p\left(E\left[H_{i}\right)\right.}{\sum_{k}^{n}=n}
$$

a. $\mathrm{P} 01=$ Melasma

$$
\begin{aligned}
& \mathrm{G} 01=\mathrm{P}\left(\mathrm{H}_{1}\right)=\frac{0.4}{2}=0.20 \\
& \mathrm{G} 03=\mathrm{P}\left(\mathrm{H}_{3}\right)=\frac{0.5}{2}=0.25 \\
& \mathrm{G} 07=\mathrm{P}\left(\mathrm{H}_{7}\right)=\frac{0.5}{2}=0.25 \\
& \mathrm{G} 10=\mathrm{P}\left(\mathrm{H}_{10}\right)=\frac{0.6}{2}=0.30
\end{aligned}
$$

b. $\mathrm{P} 02=$ Freckles

$$
\mathrm{G} 01=\mathrm{P}\left(\mathrm{H}_{1}\right)=\frac{0.4}{2.8}=0.14
$$




$$
\begin{aligned}
& \mathrm{G} 07=\mathrm{P}\left(\mathrm{H}_{7}\right)=\frac{0.8}{2.8}=0.29 \\
& \mathrm{G} 08=\mathrm{P}\left(\mathrm{H}_{8}\right)=\frac{0.6}{2.8}=0.21 \\
& \mathrm{G} 09=\mathrm{P}\left(\mathrm{H}_{9}\right)=\frac{0.2}{2.8}=0.07 \\
& \mathrm{G} 10=\mathrm{P}\left(\mathrm{H}_{10}\right)=\frac{0.8}{2.8}=0.29
\end{aligned}
$$

3. Mencari probabilitas hipotesis memandang evidence dengan cara mengalikan nilai probabilitas evidence awal dengan nilai probabilitas hipotesis tanpa memandang evidence dan menjumlahkan hasil perkalian bagi masing-masing.

$$
\sum_{k=n}^{n}=P\left(H_{i}\right) * P\left(E \mid H_{i}\right)+\ldots+P\left(H_{i}\right) * P\left(E \mid H_{i}\right)
$$

a. $\mathrm{P} 01=$ Melasma

$$
\begin{aligned}
\sum_{k=4}^{n} & =(0.4 * 0.20)+(0.5 * 0.25)+(0.5 * 0.25)+(0.6 * 0.30) \\
& =(0.08)+(0.13)+(0.13)+(0.18) \\
& =0.51
\end{aligned}
$$

b. $\mathrm{P} 02=$ Freckles

$$
\begin{aligned}
\sum_{k=5}^{n}= & (0.4 * 0.14)+(0.8 * 0.29)+(0.6 * 0.21)+(0.2 * 0.07)+(0.8 * 0.29) \\
& =(0,056)+(0.232)+(0.126)+(0.014)+(0.232) \\
& =0.66
\end{aligned}
$$

4. Mencari nilai $\mathrm{P}(\mathrm{Hi} \mid \mathrm{Ei})$ atau probabilitas hipotesis $\mathrm{H}$, dengan cara mengalikan hasil nilai probabilitas hipotesa tanpa memandang evidence dengan nilai probabilitas awal lalu dibagi dengan hasil probabilitas hipotesa dengan memandang evidence.

a. $\quad$ P01 = Melasma

$$
P\left(H_{i} \mid E_{i}\right)=\frac{P\left(H_{i}\right) * P\left(E \mid H_{i}\right)}{\sum_{k}^{n}=n}
$$

$$
\begin{aligned}
& \mathrm{P}\left(\mathrm{H}_{1} \mid \mathrm{E}\right)=\frac{0.4 * 0.20}{0.51}=0.16 \\
& \mathrm{P}\left(\mathrm{H}_{3} \mid \mathrm{E}\right)=\frac{0.5 * 0.25}{0.51}=0.25 \\
& \mathrm{P}\left(\mathrm{H}_{7} \mid \mathrm{E}\right)=\frac{0.5 * 0.25}{0.51}=0.25 \\
& \mathrm{P}\left(\mathrm{H}_{10} \mid \mathrm{E}\right)=\frac{0.6 * 0.30}{0.51}=0.35
\end{aligned}
$$

b. $\mathrm{P} 02=$ Freckles

$$
\begin{aligned}
& \mathrm{P}\left(\mathrm{H}_{1} \mid \mathrm{E}\right)=\frac{0.4 * 0.14}{0.66}=0.08 \\
& \mathrm{P}\left(\mathrm{H}_{7} \mid \mathrm{E}\right)=\frac{0.8 * 0.29}{0.66}=0.35 \\
& \mathrm{P}\left(\mathrm{H}_{\mathrm{g}} \mid \mathrm{E}\right)=\frac{0.6 * 0.21}{0.66}=0.19
\end{aligned}
$$




$$
\begin{aligned}
& \mathrm{P}\left(\mathrm{H}_{9} \mid \mathrm{E}\right)=\frac{0.2 * 0.07}{0.66}=0.02 \\
& \mathrm{P}\left(\mathrm{H}_{10} \mid \mathrm{E}\right)=\frac{0.8 * 0.29}{0.66}=0.35
\end{aligned}
$$

5. Mencari nilai bayes dari metode Teorema Bayes dengan cara mengalikan nilai probabilitas evidence awal atau $\mathrm{P}(\mathrm{E} \mid \mathrm{Hi})$ dengan nilai hipotesa $\mathrm{Hi}$ benar jika diberikan evidence $\mathrm{E}$ atau $\mathrm{P}(\mathrm{Hi} \mid \mathrm{E})$ dan menjumlahkan perkalian.

$$
\sum_{k=1}^{n} \text { Bayes }=\left(P\left(E \mid H_{1}\right) * P\left(H_{1} \mid E_{1}\right) \ldots+\left(P\left(E \mid H_{1}\right) * P\left(H_{1} \mid E_{1}\right)\right.\right.
$$

a. $\mathrm{P} 01=$ Melasma

$$
\begin{aligned}
\sum_{k=4}^{n} \text { Bayes }= & (0.4 * 0.16)+(0.5 * 0.25)+(0.5 * 0.25)+(0.6 * 0.35) \\
= & (0.06)+(0.12)+(0.12)+(0.21) \\
& =0.52
\end{aligned}
$$

b. $\mathrm{P} 02=$ Freckles

$$
\begin{aligned}
& \sum_{k=5}^{n} \text { Bayes }=(0.4 * 0.09)+(0.8 * 0.36)+(0.6 * 0.20)+(0.2 * 0.02)+(0.8 * 0.36) \\
& =(0.033)+(0.281)+(0.114)+(0,004)+(0.281)
\end{aligned}
$$

$$
=0.71
$$

Dari proses perhitungan menggunakan metode Teorema Bayes di atas, maka dapat diketahui bahwa diagnosa pasien menderita Penyakit Freckles dengan nilai keyakinan $0,71 \%$ atau $71 \%$ yang tertinggi dari jenis lain, maka pengendaliannya adalah: Siapkan 1 buah jeruk lemon belah menjadi 2 bagian., Gosokkan dengan lembut ke wajah., Sebaiknya hindari paparan sinar matahari secara langsung dengan menggunakan tabir surya(sunblock) sebelum beraktivitas di luar ruangan, Mengurangi minuman yang mengandung kafein, Perawatan dengan laser.

\subsection{Implementasi Sistem}

1. Tampilan Form Menu Utama

Berikut gambar 1 merupakan form login yang berfungsi untuk melakukan proses validasi username dan password pengguna.

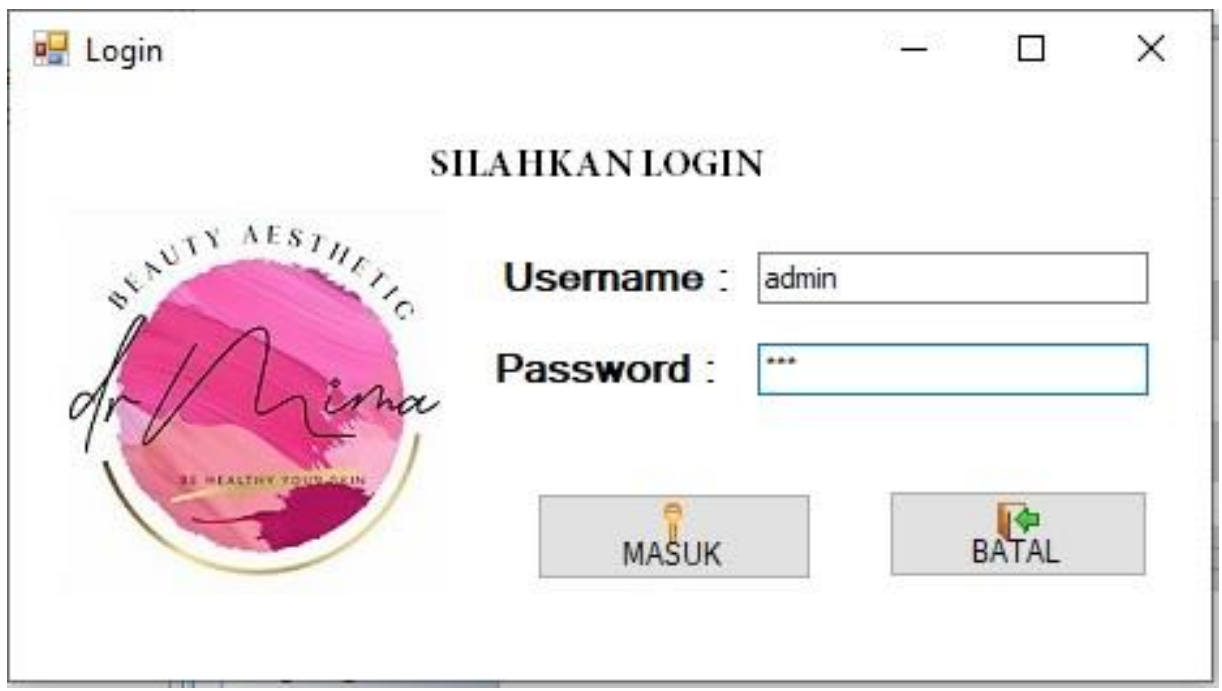

Gambar 1. Tampilan Form Login 
2. Tampilan Form Menu Utama

Berikut gambar 2 adalah tampilan dari Form Data Penyakit adalah form untuk menginput data penyakit.

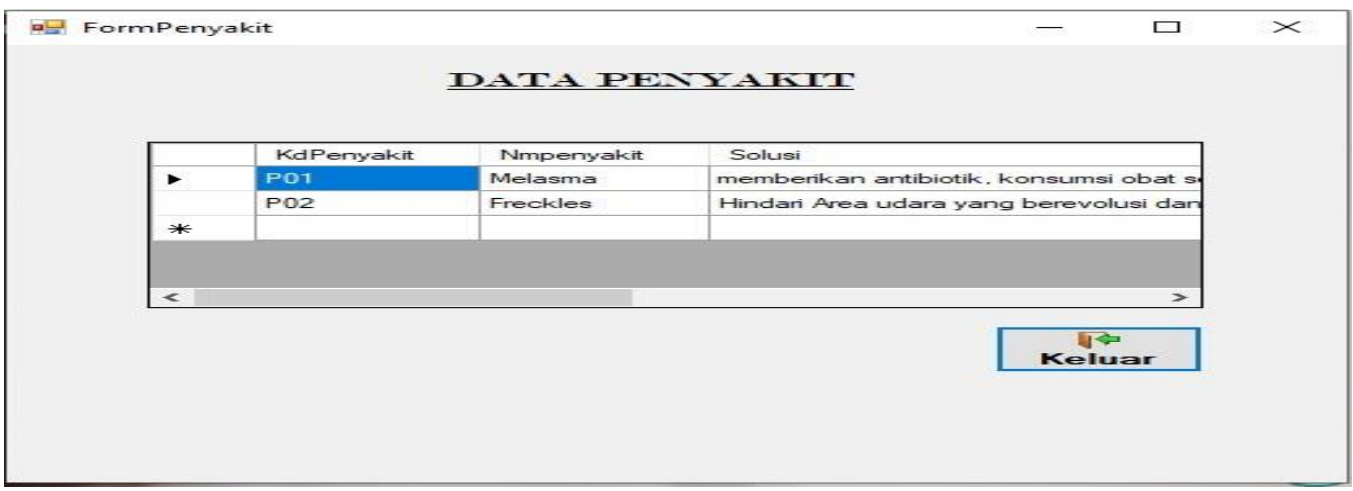

Gambar 2. Form Data Penyakit

\section{Tampilan Data Gejala}

Berikut gambar 3 adalah tampilan dari Form Data Gejala adalah form untuk menginput data gejala.

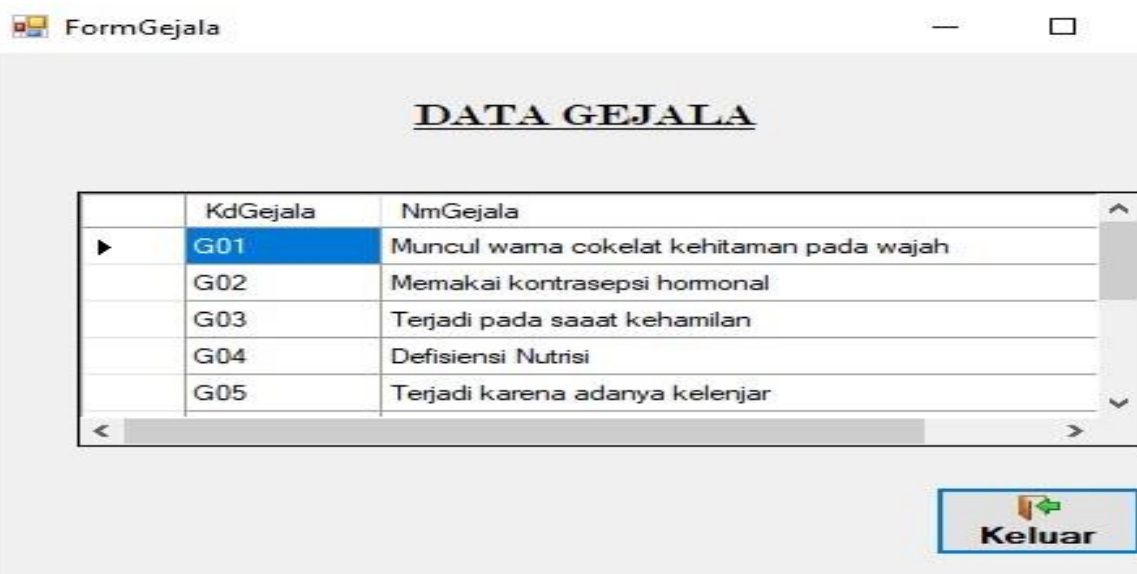

Gambar 3. Form Data Gejala

4. Tampilan Data Pasien

Berikut gambar 4 adalah tampilan dari Form Data Pasien adalah form untuk menginput data pasien. 몹 FormPasien

\section{DATA PASIEN}

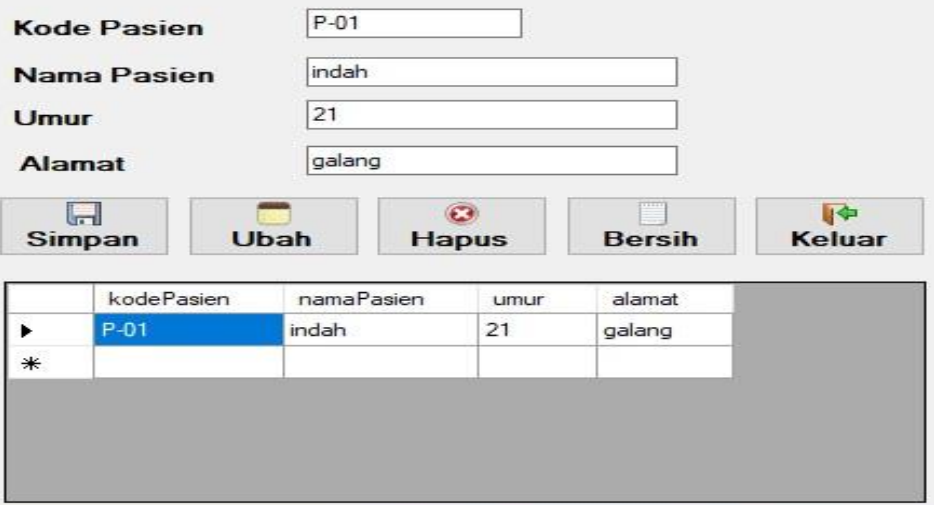

Gambar 4. Form Data Pasien 
5. Tampilan Data Basis Aturan

Berikut gambar 5 adalah tampilan dari Form Data Basis Aturan adalah untuk menginput data basis aturan.

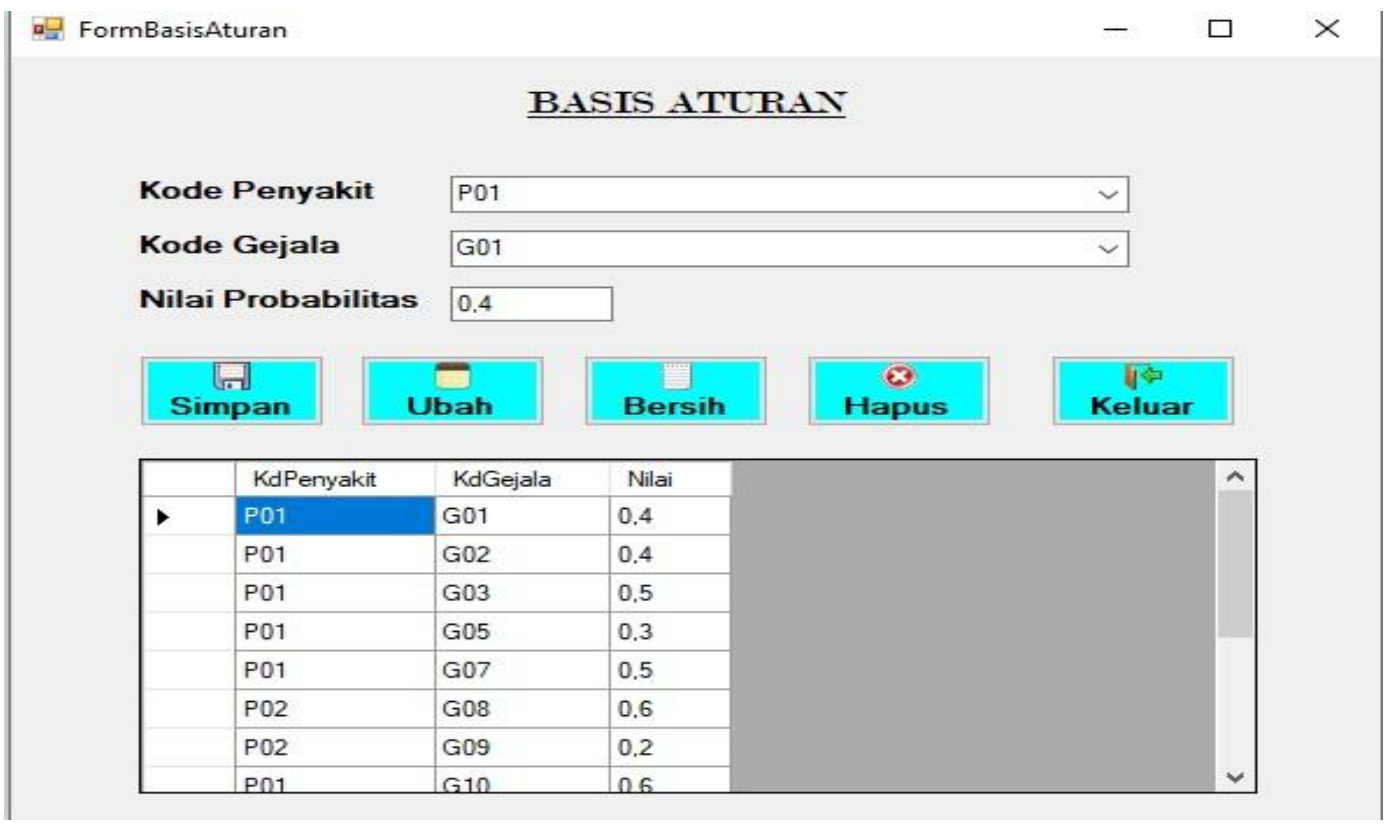

Gambar 5. Form Data Basis Aturan

6. Tampilan Form Diagnosa

Berikut gambar 6 adalah tampilan dari Form Diagnosis adalah tampilan yang berisis perhitungan dengan menggunakan metode Teorema Bayes.

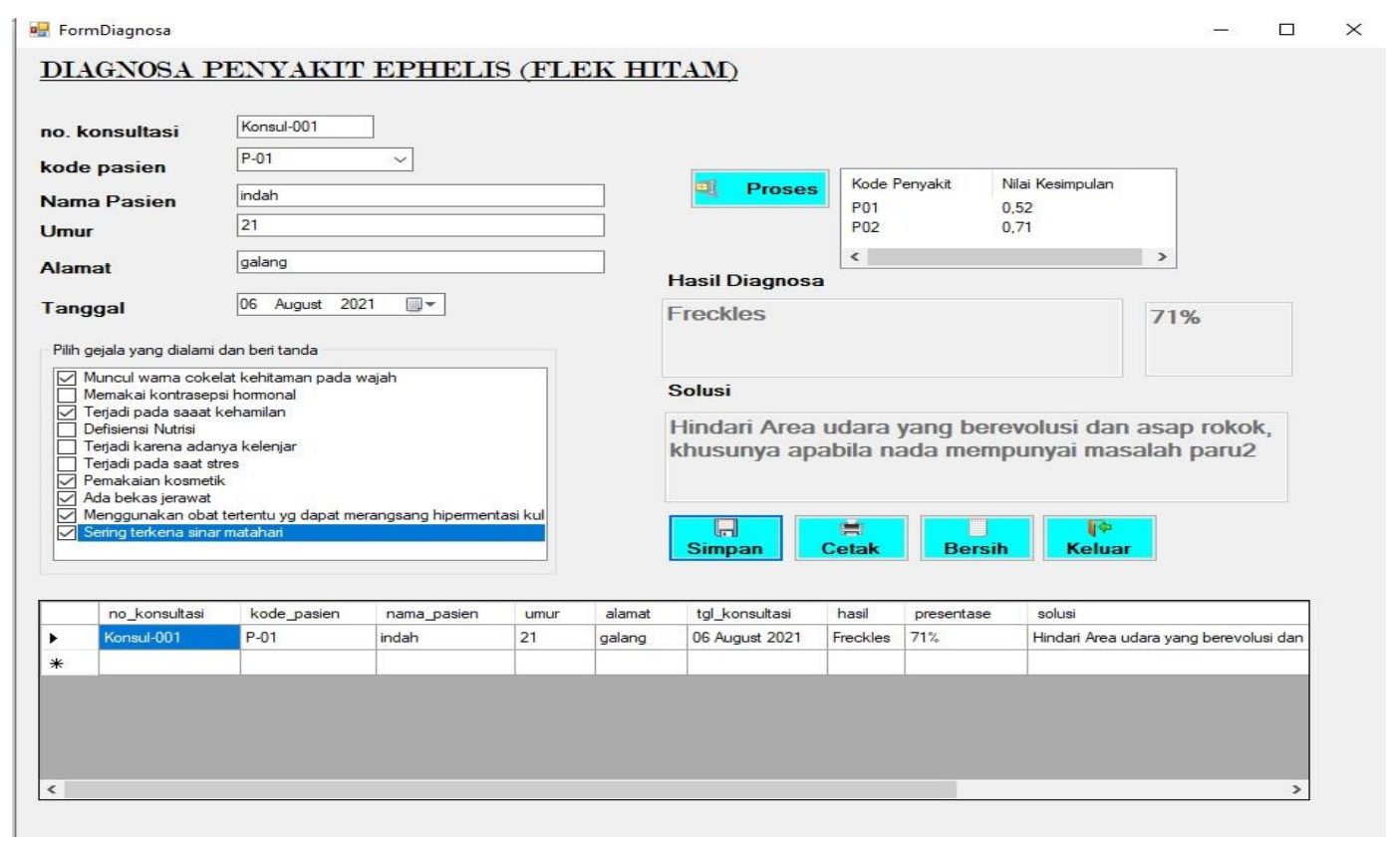

Gambar 6. Form Diagnosa 
7. Tampilan Laporan

Berikut gambar 7 adalah tampilan dari laporan yang berfungsi untuk melihat laporan dari hasil prodes diagnosis penyakit dengan metode Teorema Bayes.

KLINIK DR. MIMA BEAUTY AESTHETIC

LAPORAN HASIL DIAGNOSA PENYAKIT EPHELIS (FLEK HITAM)

\begin{tabular}{|c|c|}
\hline Tanggal & 17 September 2021 \\
\hline Waktu & $12: 09: 35 \mathrm{PM}$ \\
\hline No Konsultasi & Konsul-001 \\
\hline Kode Pasien & P-01 \\
\hline Nama Pasien & indah \\
\hline Gejala & $\begin{array}{l}\text { Sering terkena sinar matahari, Menggunakan obat tertentu yg dapat merangsang hipermentas kulit, Ada } \\
\text { bekas jerawat, Pemakaian kosmetik, Terja di pada saaat kehamilan, Muncul wama cokelat kehitaman pada } \\
\text { wajah. }\end{array}$ \\
\hline Hasil & Freckles \\
\hline Persentase & $71 \%$ \\
\hline Solusi & $\begin{array}{l}\text { Siapkan } 1 \text { buah jeruk lemon bel ah menj adi } 2 \text { bagian. Gosokkan dengan lembut ke wajah. Sel ain itu seb aikny } \\
\text { hindari paparan sinar matahari secara langsung dengan menggunakan tabir surya at au sunscreen sebelum } \\
\text { beraktivitas di luar ruangan. }\end{array}$ \\
\hline
\end{tabular}

Medan, 06/08/2021

Diketahui,

Dr. Emmya Pertiwi Nangin

Gambar 7. Tampilan Laporan

Sistem Pendukung Keputusan ini dapat memudahkan Kepala Sekolah dalam mengolah hasil evaluasi tenaga pengajar.

\section{KESIMPULAN}

Setelah dilakukan implemantasi program dan pengujian yang dilakukan pada bab sebelumnya, maka dapat diambil beberapa kesimpulan sebagai berikut:

1. Pengujian Sistem ini dilakukan dengan cara berkonsultasi dan hasil dari konsultasi itu berdasarkan pilihan gejala dalam sistem kemudian sistem akan mencari nilai Probabilitas dan mencari nilai kesimpulan dari Teorema Bayes sehingga sistem dapat menyimpulkan penyakit Ephelis itu sendiri dan data

2. Penerapan Metode Teorema Bayes dalam mendiagnosa penyakit Ephelis ini berdasarkan gejala-gejala yang diberikan oleh pakar kemudian sistem akan menghitung berdasarkan metode Teorema Bayes sehingga muncul nilai Probabilitas hasil diagnosa maka dapat disimpulkan hasil dari diagnosa sehingga diberikan solusi atau cara penanganannya .

3. Dalam memberikan solusi maka sistem ini dapat melakukan dengan memilih menu diagnosa yang terdapat dihalaman utama kemudian memilih gejala yang dialami setelahnya sistem akan melakukam perhitungan maka akan muncul hasil diagnosa dan solusinya.

\section{UCAPAN TERIMA KASIH}

Puji syukur dipanjatkan atas berkat Tuhan Yyang Maha Esa karena berkat dan kasih karuniaNya, yang telah memberikan kesehatan dan kesempatan sehingga dapat diselesaikan jurnal ilmiah ini dengan baik. Ucapan terima kasih ditujukan kepada orang tua, atas dukungan yang di beri baik dari segi materi dan Doa yang tiada henti-hentinya. Ucapan terimakasih juga ditujukan untuk pihak-pihak yang telah mengambil bagian dalam penyusunan jurnal ilmiah ini. 


\section{REFERENSI}

[1] S. M. Silvia Ayunda Murad, Muhammad Irsan, "Sistem Pakar Diagnosa Penyakit Kulit Wajah di Klinik Edelweiss Medical Centre Menggunakan Java Netbeans dan MySQL,” J. Informatics Eng., vol. 5, no. 1, pp. 34-42, 2017.

[2] Dr. M D Cristy Pane,Flek Hitam,ALODOKTER,April.2020.[Online]. Available: https://www.alodokter.com/flek-hitam[Akses: 8 Jan.2021].

[3] M. Dahria, "Pengembangan Sistem Pakar Dalam Membangun Suatu Aplikasi," J. Saintikom, vol. 10, no. 3, pp. 199-205, 2011.

[4] Annahl Riadi, "Perancangan Sistem Pakar Diagnosa Penyakit Diabetes Melitus Pada RSUD bum Panua Kabupaten Pohuwato", Ilkom, Vol.9, No.3, Desember 2017, pp.309-316

[5] P. Studi Sistem Informasi and S. Triguna Dharma, "SISTEM PAKAR UNTUK MENDIAGNOSA PENYAKIT ANEMIA DENGAN MENGGUNAKAN METODE TEOREMA BAYES * Trinanda Syahputra \#1 , Muhammad Dahria \#2 , Prilla Desila Putri \#3,” Saintikom, vol. 16, no. 3, pp. 284-294, 2017.

\section{BIBLIOGRAFI PENULIS}

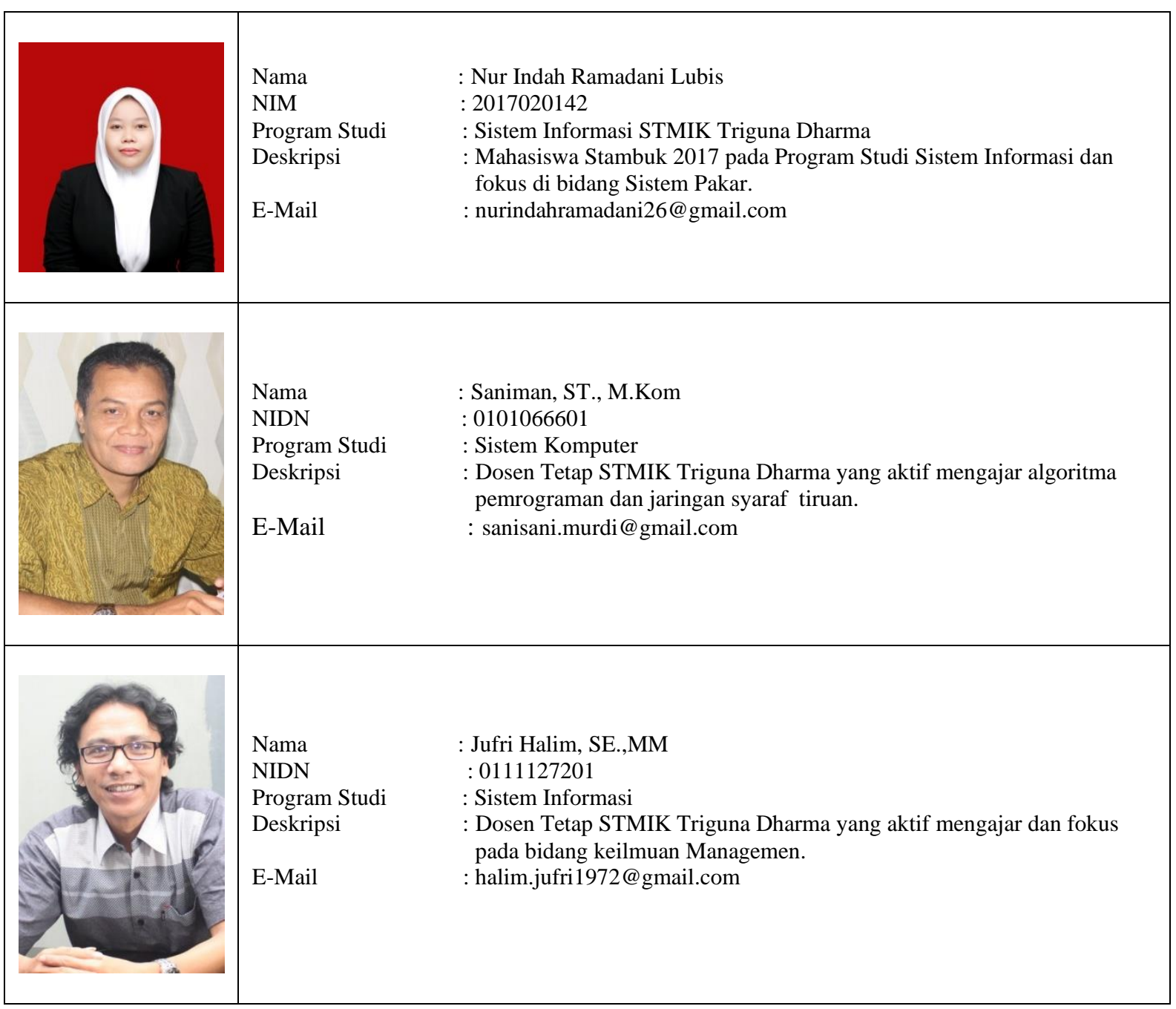

